\title{
В.В. Борщева
}

Севастопольский государственный университет, 299053 г. Севастополь, Российская Федерация

\section{Современные подходы к преподаванию в университете иностранного языка для специальных целей}

Иностранный язык для специальных целей - один из традиционных курсов университетской подготовки специалистов разных профилей и направлений, однако эффективность такого курса во многом зависит от самой учебной программы, в основе которой должны быть контекстный подход к образованию, коммуникативный подход к преподаванию языка, технология смешанного обучения, интеграция ИКТ, предметно-языковое интегрированное обучение. Массовые открытые онлайн-курсы (МООК) обладают огромным потенциалом с точки зрения актуального контента курса, поэтому они также должны быть частью учебной программы. Программа курса, включающая как минимум 3 блока: академический иностранный язык, деловой иностранный язык и профессиональный иностранный язык, должна помогать учащимся строить свою индивидуальную образовательную траекторию и формировать учебную автономию как в аудитории, так и в онлайн-среде.

Ключевые слова: иностранный язык для специальных целей, контекстный подход, технология смешанного обучения, ИКТ, предметно-языковое интегрированное обучение, MOOK

ССЫЛКА НА СТАТЬЮ: Борщева В.В. Современные подходы к преподаванию в университете иностранного языка для специальных целей // Педагогика и психология образования. 2020. № 2. C. 73-82. DOI: 10.31862/2500-297X-20202-73-82 
DOI: $10.31862 / 2500-297 X-2020-2-73-82$

\section{Borshcheva}

Sevastopol State University,

Sevastopol, 299053, Russian Federation

\section{Modern approaches to teaching ESP at University}

ESP is one of traditional university courses for training various specialists in a number of directions, but the effectiveness of such course depends a lot on the particular curriculum which should be based on the context approach to education, communicative approach to teaching languages, ICT integration and CLIL. MOOCs have a great potential from the point of view of the content of the course, and they should be included in the curriculum. In general, the curriculum should contain 3 modules: Academic English, Business English, and Professional English, that should help learners form personal learning path as well as develop learner autonomy both in the classroom and online.

Key words: ESP, context approach, blended learning, ICT, CLIL, MOOC

CITATION: Borshcheva V.V. Modern approaches to teaching ESP at university. Pedagogy and Psychology of Education. 2020. No. 2. Pp. 73-82. (In Russ.). DOl: 10.31862/2500-297X-2020-2-73-82

Курс «Иностранный язык для специальных целей» является довольно традиционным в отечественной системе образования и реализуется для всех неязыковых направлений подготовки, как на бакалавриате, так и в магистратуре. Даже если в учебном плане бакалавриата или магистратуры стоит курс с названием «Иностранный язык», то преподавание все равно включает профессиональную терминологию и акцент на профиль учащихся в той или иной мере. Курс носит традиционное название, являясь калькой с англоязычного ESP (English for Specific Purposes), нередко его переименовывают в «Иностранный язык для профессиональных целей», «Профессиональный иностранный язык» и прочие, но суть остается той же. Однако в разных вузах и разными кафедрами этот курс реализуется по-разному, в его содержание включаются 
совершенно различные блоки, элементы, нет единых требований ни по содержанию, ни по результатам обучения, которые довольно размыто формулируются в какую-то компетенцию типа «способность к коммуникации в устной и письменной формах на русском и иностранных языках для решения задач межличностного и межкультурного взаимодействия» (https://gos.ru/). Из такой формулировки, например, не вытекает напрямую никакого содержания, трактовать можно как угодно, как удобно, поэтому и качество курса зачастую зависит только от конкретного преподавателя, системности и последовательности в этом процессе добиваться сложно. А между тем курс специального иностранного языка крайне важен во многих отраслях.

В данной статье будут рассмотрены подходы к дизайну и разработке такого курса, актуальные сегодня, апробированные в нескольких вузах Российской Федерации (Московский государственный гуманитарный университет им. М.А. Шолохова, Московский педагогический государственный университет, Севастопольский государственный университет) в течение 2009-2020 гг. Длительная апробация разных подходов к реализации данного курса позволяет описать и систематизировать наиболее эффективные из них для построения учебной программы согласно требованиям ФГОС, а также отвечающие вызовам сегодняшнего дня. Курс «Иностранный язык для специальных целей» уже становится не столько языковым курсом, сколько профессионально-значимой дисциплиной, помогающей учащимся развиваться, формировать автономию в обучении и выстраивать собственную образовательную траекторию.

Преподавание иностранного языка на неязыковых направлениях подготовки традиционно направлено на овладение иноязычной профессиональной терминологией, в первую очередь через тексты, поэтому на протяжении многих десятилетий программа обучения строилась на текстовом материале (адаптированные и аутентичные тексты), задания на понимание содержания (именно поэтому аннотирование и реферирование текстов прочно заняли свое место в программах обучения даже в аспирантуре), работу с терминологией. В советские времена этого было вполне достаточно, для большинства учащихся и самих преподавателей другого формата и других целей не было: страна была закрытой, и в целом во всей системе образования преподавание иностранных языков было в определенной мере искусственным процессом, далеким от жизненных ситуаций. Но уже в конце 1990-х начале 2000-х гг., когда открылись границы, появились зарубежные учебники и самое важное - появились возможности общения на иностранном языке в деловой, рабочей среде, преподавание языков начало медленно, но неизбежно меняться по формату, подходам, методикам. 
Но несмотря на это в нашей стране не все выпускники вузов могут свободно пройти собеседование на иностранном языке, выступить с презентацией, поучаствовать в переговорах, хотя неплохо знают грамматику, много прочли текстов и отлично владеют терминологией. Это проблема системного характера, для решения которой необходим пересмотр подходов к реализации программы обучения.

В основе курса «Иностранный язык для специальных целей» должно быть то содержание, которое наиболее приближено к реальной профессиональной деятельности учащихся, т.е. если это курс обучения студентов-юристов, то обязательно изучение юридической документации, законов, постановлений и прочего, а коммуникативная деятельность должна имитировать контекст профессиональной, например, судебное заседание, расследование и т.д.

Одной из проблем в преподавании иностранного языка для профессиональных целей является отсутствие единого учебника, рекомендованного для вузов, но это легко объяснимо спецификой предметной области каждого направления, а также высокими темпами развития науки и знания. Повсеместно в вузах издаются авторские учебники для разных направлений, ведущие зарубежные издательства публикуют целые специализированные курсы для юристов, медиков, инженеров и т.д., можно также отметить специальные серии, типа Professional English in Use издательства Кембриджского университета. Однако большим недостатком всех перечисленных изданий является их стремительное устаревание буквально через несколько лет, особенно в тех сферах, где прогресс идет более стремительно.

На наш взгляд, сегодня говорить о важности учебника как центрального элемента учебной программы нельзя, программа обучения должна строиться совершенно иным образом, на основе подходов и принципов, определяющих ее содержание и направленность. Поэтому именно для профессионально-ориентированного курса иностранного языка теория контекстного образования, разработанная А.А. Вербицким и его научной школой, наиболее подходит как теоретическая база и основа для практической реализации. Согласно автору теории, основная идея контекстного образования - «наложить усвоение обучающимся теоретических и иных знаний на “канву” усваиваемой им профессиональной и практической деятельности» [10, с. 53], что абсолютно соответствует целям курса иностранного языка для специальных целей.

Мы выделяем контекстный подход в качестве ключевого в проектировании курса иностранного языка для специальных целей. В рамках контекстного образования А.А. Вербицкий отмечает несколько 
базовых форм деятельности, которые в том числе хорошо накладываются и на предметное преподавание иностранного языка, а именно: «учебная деятельность академического типа, квазипрофессиональная деятельность и учебно-профессиональная деятельность» [7, с. 130].

Учебная деятельность академического типа-это традиционные формы обучения через тексты, усвоение грамматических правил, выполнение лексических упражнений и т.д., квазипрофессиональная деятельность это те активности, которые имитируют реальную профессиональную деятельность, например, ролевые игры типа собеседования при устройстве на работу, кейсы по решению проблемных ситуаций и т.д., и учебнопрофессиональная деятельность - когда студент выполняет вполне реальные задачи из сферы своей профессиональной деятельности, это наиболее приближенная к реальной жизни работа, именно она и является наиболее продуктивной в учебном процессе, но не всегда реализуется в должном объеме. Все эти формы деятельности должны быть учтены при составлении программы обучения и быть взаимосвязанными, чтобы комплексно формировать иноязычную профессионально-ориентированную коммуникативную компетенцию, которую мы считаем базовой компетенцией такого курса.

Контекстный подход важен не только при выборе учебного контента, но и при выборе форм и методов работы. Например, для студентовюристов актуальны кейсы по изучению криминальных расследований или ролевые игры и симуляции, имитирующие действия из профессиональной области (проведение слушания по делу, опрос свидетелей и т.д.). Для студентов-физиков более подходящей формой будет работа по написанию научной статьи и ее обсуждение, рецензирование научных материалов, описание эксперимента, разбор алгоритма подачи статьи к публикации, участие в научной конференции и т.д. По каждому направлению подготовки можно выделить ключевые направления работы и построить образовательную программу на их основе.

Близким к этому подходу можно считать предметно-языковое интегрированное обучение (CLIL), которое зародилось на западе в конце 1990-х гг., и традиционно было больше связано с системой школьного образования. Потенциал технологии может быть хорошо использован и для вузовского обучения, поскольку оно сочетает в себе и междисциплинарность, и языковую коммуникативную практику. В рамках этого подхода язык - не предмет обучения, а средство обучения. В исследовательской литературе подчеркивается, что при этом подходе «использование языка в смысловом контексте развивает языковые компетенции обучающихся естественным путем» [11, с. 61], что соотносится с целями курса 
профессионально-ориентированного иностранного языка. CLIL включает в себя 4 "C": “content" (содержание), “communication" (коммуникация), “cognition" (когнитивность), "culture” (культура) [14]. Практикующие преподаватели иностранных языков, использующие предметно-языковое интегрированное обучение на занятиях в университете, отмечают его высокую эффективность именно в профессиональной сфере обучаемых [13, с. 169], что опять же соотносится со спецификой курса иностранного языка для специальных целей.

В рамках этого подхода можно также говорить об интеграции массовых открытых онлайн-курсов (МООК) в программу обучения. К МООК в педагогической литературе относят онлайн-курсы (учебно-методические комплексы), имеющие в своей структуре теоретический материал в виде лекций (чаще это видеолекции, сопровождающиеся письменным скриптом текста, озвученного на видео), разного рода задания для самостоятельной работы и отработки этого материала, а также контроль (он может быть в форме тестов и финального задания (экзамена), т.е. традиционную модель обучения в целом, но в ином формате [2].

В многочисленных исследованиях, связанных с использованием МООК в преподавании иностранных языков, практикующие преподаватели отмечают положительную динамику в языковом и профессиональном прогрессе студентов [1-3; 6; 9; 12], однако это происходит, когда студенты не изучают МООК самостоятельно, а делают это в рамках курса, под контролем или мониторингом преподавателя. Но это отдельная тема, в которую в данной статье не будем углубляться. Отметим только, что потенциал МООК именно для курса иностранного языка для специальных целей довольно велик, поскольку большинство онлайн-курсов разработаны на самых новейших и актуальных материалах и покрывают те темы, которые в учебники попадут спустя какое-то время, поскольку издание учебных материалов - долгий, кропотливый труд, а конкуренция между онлайн-курсами довольно высока и привлекают они учащихся именно актуальным, современным контентом. Поэтому через МООК учащиеся могут значительно быстрее освоить инновационные аспекты профильных дисциплин, а также послушать лекции ведущих специалистов в своей области. Таким образом, МООК - это еще один инструмент для повышения профессионально-значимых компетенций через иностранный язык. Интегрировать МООК в учебный процесс лучше всего в формате самостоятельной работы, чтобы у учащихся был выбор курса, возможность осваивать его в своем собственном темпе. Каждый семестр рекомендуется проходить не менее одного онлайн-курса длительностью 6-8 недель, тогда этот курс будет более глубоким, а не ознакомительным. 
Следующим важным и актуальным подходом является интеграция ИКТ в процесс преподавания курса для специальных целей, и речь идет не только о МООК, а о построении электронной образовательной среды, в которой множество элементов взаимодополняют друг друга и дают широкий спектр коммуникативной практики. Технология смешанного обучения именно для курса иностранного языка для специальных целей имеет большую важность и значение, поскольку, как уже было отмечено выше, традиционные учебники не успевают за прогрессом времени, а в электронной среде можно довольно оперативно менять контент, добавлять новые виды и формы заданий, тем самым актуализируя содержание курса и возможности его использования. Технология смешанного обучения дает возможности для формирования учебной автономии [5] и индивидуальной образовательной траектории [4], которые сегодня являются также важными показателями успешности обучения.

Исходя из запросов реальной жизни, трудовых функций специалистов и области профессиональной деятельности, можно выделить несколько универсальных блоков, которые должны быть в курсе иностранного языка для специальных целей и формировать иноязычную профессионально-ориентированную коммуникативную компетенцию: академический иностранный язык, деловой иностранный язык, профессиональный иностранный язык.

Академический иностранный язык в первую очередь связан с теми учебными навыками, которые необходимы учащимся для учебы в целом, развивает не только языковые навыки, но и критическое мышление студентов [8], формирует навыки академического письма, необходимого для дальнейшей учебы или исследований. Сегодня именно академический иностранный язык является основой курса ESP, это костяк, формирующий необходимые навыки и компетенции. В этот блок необходимо включить научно-академический контент, т.е. написание и оформление научной статьи, аннотации к ней, работа с базами научных данных, участие в научных мероприятиях - конференциях, круглых столах, т.е., то, что сегодня востребовано во всех сферах - умение представить результаты собственных исследований.

Деловой иностранный язык - это блок, связанный с деловой коммуникацией: переписка (сегодня более актуальна будет интернет-переписка, конечно), деловые переговоры, встречи, деловой этикет и его межкультурные различия, презентации. Эта часть больше ориентирована на развитие коммуникативных навыков межкультурного и делового общения.

Профессиональный иностранный язык уже больше связан непосредственно с направлением подготовки учащихся. В этом разделе изучается терминология, но не для того, чтобы уметь переводить тексты, 
реферировать или аннотировать их, а для того, чтобы уметь свободно общаться с представителями других стран и культур в рамках своей профессиональной деятельности. Поэтому важным аспектом при составлении программы должен быть коммуникативный подход, ставящий акценты на постоянной коммуникации при изучении материала. Поскольку дефицит учебных часов - это также типичная ситуация для большинства вузов нашей страны, именно технология смешанного обучения, когда множество форм работы для разного типа учащихся, в том числе и для разного уровня учащихся, дает возможность создать условия для эффективной работы.

Курс «Иностранный язык для специальных целей» сегодня приобретает новое значение, у учащихся появилась возможность через иностранный язык повышать уровень профессиональной грамотности и формировать не только иноязычную коммуникативную компетенцию, но и профессиональные компетенции, поскольку сегодня содержание курса ESP может быть настолько инновационным, насколько позволяют современные технологии. Курс должен базироваться на ряде подходов, среди которых первостепенное значение имеет контекстный подход (научная школа А.А. Вербицкого); коммуникативный подход; технология смешанного обучения со всеми инструментами ИКТ, которые сегодня актуальны, в том числе интеграция МООК; предметно-языковое интегрированное обучение, позволяющее использовать язык в качестве инструмента познания. Принципиально важными блоками курса ESP являются академический иностранный язык, деловой иностранный язык и профессионально-ориентированный иностранный язык. Реализация данной программы обучения требует от преподавателя творческого подхода к работе, поиска новых материалов, ресурсов, идей.

\section{Библиографический список / References}

1. Агафонова Л.И. Массовые открытые онлайн курсы: возможности и сложности интеграции в процесс обучения иностранным языкам // Иноязычное образование и межкультурная коммуникация в поликультурном пространстве: Сборник научных трудов. СПб., 2019. С. 3-6. [Agafonova L.I. Mass open online courses: Opportunities and difficulties of integration into the process of teaching foreign languages. Inoyazychnoe obrazovanie $i$ mezhkulturnaya kommunikatsiya v polikulturnom prostranstve. St. Petersburg, 2019. Pp. 3-6. (In Russ.)]

2. Борщева В.В. Особенности использования массовых открытых онлайн-курсов в обучении иностранному языку для специальных целей // Вестник Пермского национального исследовательского политехнического университета. Проблемы языкознания и педагогики. 2017. № 1. С. 86-95. [Borshcheva V.V. Peculiarities of using mass open online courses in teaching 
a foreign language for special purposes. PNRPU Linguistics and Pedagogy Bulletin (Vestnik PNIPU. Problemy âzykoznaniâ i pedagogiki). 2017. No. 1. Pp. 86-95. (In Russ.)]

3. Борщева В.В., Кашпарова В.С., Синицын В.Ю. Использование массовых открытых онлайн-курсов в обучении английскому языку студентов нелингвистических направлений подготовки // Педагогика и психология образования. 2017. № 1. C. 45-54. [Borshcheva V.V., Kashparova V.S., Sinitsyn V.Yu. Using mass open online courses in teaching English to students of non-linguistic areas of training. Pedagogy and Psychology of Education. 2017. No. 1. Pp. 45-54. (In Russ.)]

4. Борщева О.В. Индивидуальная образовательная траектория как условие эффективного обучения // Вопросы педагогики. 2019. № 8-2. С. 24-27. [Borshcheva O.V. Individual educational trajectory as a condition of effective training. Voprosy pedagogiki. 2019. No. 8-2. Pp. 24-27. (In Russ.)]

5. Борщева О.В. Формирование автономии студентов при обучении иностранному языку // Вопросы лингводидактики и межкультурной коммуникации в контексте современных исследований: Сборник научных статей XI Международной научно-практической конференции / Отв. ред. Н.В. Кормилина, Н.Ю. Шугаева. Чебоксары, 2019. С. 101-105. [Borshcheva O.V. Formation of student autonomy in teaching a foreign language. Voprosy lingvodidaktiki $i$ mezhkulturnoy kommunikatsii v kontekste sovremennykh issledovaniy. N.V. Kormilina, N.Y. Shugaeva (eds.). Cheboksary, 2019. Pp. 101-105. (In Russ.)]

6. Валеева Н.Г., Руднева М.А. Массовые открытые онлайн-курсы в обучении студентов экологического факультета английскому языку для профессиональной коммуникации // Вестник РУДН. Серия: Экология и безопасность жизнедеятельности. 2016. № 3. С. 99-105. [Valeeva N.G., Rudneva M.A. Mass open online courses in the training of students of the environmental faculty in English for professional communication. RUDN Journal of Ecology and Life Safety. 2016. No. 3. Pp. 99-105. (In Russ.)]

7. Вербицкий А.А. Иноязычное образование в контексте профессии // Вестник Московского государственного лингвистического университета. Образование и педагогические науки. 2018. № 2 (796). С. 126-141. [Verbitsky A.A. Foreign language education in the context of the profession. Vestnik of Moscow State Linguistic University. Education and Teaching. 2018. No. 2 (796). Pp. 126-141. (In Russ.)]

8. Городецкая Л.А. Критическое мышление и обучение английскому языку для академических целей // Вестник Московского университета. Серия 19: Лингвистика и межкультурная коммуникация. 2017. № 4. С. 32-40. [Gorodetskaya L.A. Critical thinking and English language education for academic purposes. Vestnik Moskovskogo universiteta. Seriya 19: Lingvistika i mezhkulturnaya kommunikatsiya. 2017. No. 4. Pp. 32-40. (In Russ.)]

9. Малинин Н.В. Использование массовых открытых онлайн-курсов в преподавании иностранных языков на неязыковых факультетах вузов // Филологические науки. Вопросы теории и практики. 2019. Т. 12. № 2. С. 258-261. [Malinin N.V. Using mass open online courses in teaching foreign languages at non-language faculties of universities. Philological Sciences. Issues of Theory and Practice. 2019. Vol. 12. No. 2. Pp. 258-261. (In Russ.)] 
10. Психология и педагогика контекстного образования / Под науч. ред. А.А. Вербицкого. М.; СПб., 2018. [Psikhologiya i pedagogika kontekstnogo obrazovaniya [Psychology and pedagogy of context education]. A.A. Verbitsky (ed.). Moscow; St. Petersburg, 2018.]

11. Роль предметно-языкового интегрированного обучения (CLIL) в условиях полиязычного образования / Сыдык Л.С., Книсарина М.М., Егизбаева Л.Е. и др. // Медицинский журнал Западного Казахстана. 2018. № 4 (60). C. 57-62. [Sydyk L.S., Knisarina M.M., Egizbaeva L.E. et al. The role of subject-language integrated learning (CLIL) in multilingual education. Medical Journal of West Kazakhstan. 2018. No. 4 (60). Pp. 57-62. (In Russ.)]

12. Чекун О.А. Интеграция массовых открытых онлайн-курсов в обучение иностранному языку студентов неязыковых специальностей МПГУ // Педагогика и психология образования. 2016. № 1. С. 71-74. [Chekun O.A. Integration of mass open online courses in foreign language education of students of non-language specialties of MPGU. Pedagogy and Psychology of Education. 2016. No. 1. Pp. 71-74. (In Russ.)]

13. Чекун О.А. Предметно-языковое интегрированное обучение в неязыковых вузах // Педагогика и психология образования. 2019. № 1. С. 163-170. [Chekun O.A. Subject-language integrated education in non-language universities. Pedagogy and Psychology of Education. 2019. No. 1. Pp. 163-170. (In Russ.)]

14. Bentley K. The TKT Course CLIL Module. Cambridge University Press. 2010.

Статья поступила в редакцию 09.01.2020, принята к публикации 17.02.2020

The article was received on 09.01.2020, accepted for publication 17.02.2020

\section{Сведения об авторе / About the author}

Борщева Вероника Владимировна - кандидат педагогических наук, доцент; заведующий кафедрой иностранных языков Института общественных наук и международных отношений, Севастопольский государственный университет

Veronika V. Borshcheva - PhD in Pedagogy; Head at the Department of Foreign Languages of the Institute of Social Sciences and International Relations, Sevastopol State University

E-mail: veronicaengels@gmail.com 